\title{
RISK FACTORS AND FETOMATERNAL OUTCOME IN PREGNANCY WITH THROMBOCYTOPENIA.
}

1. MBBS, MS

Senior Registrar

Department of Obstetrics \&

Gynaecology

Peoples University of Medical \& Health Sciences, Nawabshah.

2. MBBS, FCPS

Assistant Professor

Department of Obstetrics \&

Gynaecology

Gambat Institute of Medical

Sciences Khairpur Mirs.

3. MBBS, M.Phil

Associate Professor

Department of Physiology

Peoples University of Medical \&

Health Sciences, Nawabshah.

4. MBBS, FCPS

Assistant Professor

Department of Obstetrics \&

Gynaecology

Gambat Institute of Medical

Sciences Khairpur Mirs.

5. MBBS, (MD)

Postgraduate Student of Medicine Peoples University of Medical \&

Health Sciences, Nawabshah.

Correspondence Address:

Dr. Aasma Naz Qureshi

Department of Obstetrics \&

Gynaecology

Peoples University of Medical \&

Health Sciences, Nawabshah.

aasma.naz@yahoo.com

Article received on:

09/01/2019

Accepted for publication:

$30 / 04 / 2019$

\begin{abstract}
Aasma Naz Qureshi', Sakina ${ }^{2}$, Tabinda Taqi ${ }^{3}$, Hafiza Khatoon ${ }^{4}$, Irfan Ahmed ${ }^{5}$
ABSTRACT... Objectives: To find out the risk factors and their effects on mother and fetus in pregnancy with thrombocytopenia. Study Design: Cross sectional study. Setting: Department of Obstetrics and Gynaecology at Liaquat University Hospital Hyderabad. Period: Six months (1st July 2016 to 31st December 2016). Material and Methods: Total 96 patients with gestational age $>24$ weeks having platelet count below 150X109/L were included in the study. Patients admitted throughout patient clinic department of obstetrics \& Gynecology at Liaqat University Hospital. Those patients having platelet count below $150 \times 10^{\circ} / \mathrm{L}$ were registered for study. Proforma filled which include Patients demographics details, gestational age, complete blood count (Having platelet count) other important investigations like coagulation profile (PT, APTT), Ultrasound and LFT noted in proforma SPSS version used for analysis. Descriptive statics were calculated frequency and percentages were drawn for the study. Results: Risk factors related to thrombocytopenia included PIH18 (18.8\%), preeclampsia 14(14.6\%), eclampsia 10(10.3\%), HELLP Syndrome $6(6.3 \%)$, Viral Hepatitis $12(12.5 \%)$ and in $36(37.5 \%)$ no risk factors was found. Maternal complication were placental abruption21 (21.8\%) post partam hemorrhage 14(14.6\%). 7(7.3\%) were transferred to ICU and 02(2.1\%) maternal death was seen. Fetal outcome include low Apgar score of $<6$ in $17(17.7 \%)$, low birth weight $16(16.7 \%)$ and NICU admission $11(11.5 \%)$. Conclusion: Thrombocytopenia is a common finding in pregnancy careful diagnosis is important to distinguish serious causes from mild then to manage mother and fetus appropriately. Thrombocytopenia in pregnancy is associated with adverse maternal and fetal outcome in significant number of pregnant woman.
\end{abstract}

Key words: $\quad$ Fetal Outcome, Maternal Health, Risk Factors, Thrombocytopenia.

Article Citation: Qureshi AN, Sakina, Taqi T, Khatoon H, Ahmed I. Risk factors and fetomaternal outcome in pregnancy with thrombocytopenia. Professional Med J 2019; 26(11):1942-1946. DOI: 10.29309/TPMJ/2019.26.11.3396

\section{INTRODUCTION}

Thrombocytopenia is simply defined as platelet count below 50,000 per micro liter. Decreased platelet count is particulraly due to hematologic disorders. ${ }^{1-3}$ Other causes of thrombocytopenia include pre-eclampsia, HELLP syndrome and ITP. This disease affects $6 \%$ to $15 \%$ of all pregnant women usually at the end of pregnancy and is moderate. It is the common and frequent hematologic disorder in pregnancy apart from anemia. The most common cause of thrombocytopenia during pregnancy is the gestational thrombocytopenia which occurs in $3^{\text {rd }}$ trimester of pregnancy. This cause needs no treatment but resolves spontaneously. ${ }^{4,5}$

Gestational thrombocytopenia is defined as thrombocytopenia during pregnancy and platelet count is more than $70,000 / \mu \mathrm{L} .{ }^{6}$ The pathophysiology entails that the fetus waste products into mothers blood increases the activitivty of spleen of mother which removes blood cells quickly causing destruction of platelets. ${ }^{7}$ Patients usually present with no any alarming symptom/sign due to gestational thrombocytopenia. Bleeding from nose, gums, hematuria, splenomegaly, bruises, jaundice and petechiae. $^{8}$

The diagnosis of gestational thrombocytopenia is challenging and is difficult to differentiate between ITP and Gestational thrombocytopenia. ${ }^{9}$ If pregnant patient has previous history of ITP, she cannot be diagnosed as gestational 
thrombocytopenia. Complete blood count is advised that shows decreased platelet count. Platelet antiobodies are done to detect other causes like quinine. Bleeding time and clotting time is assessed. ${ }^{10}$ Ultrasound of spleen is done to diagnose the over activity of the organ. Bone marrow aspiration and biopsy both are done ${ }^{11}$. There is no specific treatment for gestational thrombocytopenia. Pregnant lady has to perform her normal activities and the treatment for the well being of baby and lady accordingly. ${ }^{12}$ If pregnant lady had ITP, treatment should be done with corticosteroids or intravenous immunoglobulin. ${ }^{13}$ Gestational thrombocytopenia resolves spontaneously after 1-2 months of delivery and platelet count becomes normal. Prognosis in these cases is excellent without any remedy. ${ }^{14}$

The rationale of our study is find out the risk factors and effects of thrombocytopenia on pregnant mother and fetus as well in order to develop awareness among the patients regarding this disease during pregnancy.

\section{METHOD}

This cross-sectional study includes 96 patients, conducted in the Obstetrics and Gynecology Unit II at the Liaquat University Hospital in Hyderabad. Any age and parity of all pregnant women associated with gestational age more than 24 weeks. Complete blood count (CBC) revealed thrombocytopenia cut off value of platelet $<150000 / \mu \mathrm{L}$ were included in this study, The predesigned proforma, having complete bio data, gestational period, symptomatology, clinical findings, investigations like complete blood count, platelet count, coagulation profile (prothrombin time, activated partial thromboplastin time), ultrasound examination and liver function test. Exclusion Criteria were all non pregnant patients with thrombocytopenia, gestational age $<24$ weeks, postpartum women and Non willing patients.

\section{RESULTS}

A total of 86 Women with GDM attending OPD for antenatal care at tertiary care hospital Hyderabad were included in this study. Most of the women were 28 to 40 years of age as shown in Table-l.
The average age of the women was $31.88 \pm 3.04$ years similarly mean parity and gestational age of the women is also given in Table-I.

Frequency of Risk Factors leading to thrombocytopenia were $\mathrm{PIH}$ in18(18.8\%) cases followed by preeclampsia in 14 (14.6\%) cases, eclampsia in 10(10.3\%) cases, HELLP syndrome in $06(6.3 \%)$ cases, viral Hepatitis in $12(12.5 \%)$ cases and No Risk in 36(37.5\%) cases (Figure-1).

In our study maternal outcome related to thrombocytopenia were observed and Placental Abruption in $21(21.8 \%)$ cases, followed by Post Partum Hemorrhage in $14(14.6 \%)$ cases (Figure-2).

Fetal outcome related to thrombocytopenia were observed and Low Birth Weight in 16(16.7\%) cases, meconium Stained Liquor in $7(7.3 \%)$ cases and need NICU admission in 11(11.5\%) cases (Figure-3).

\begin{tabular}{|l|c|c|}
\hline Descriptive & Mean & $\begin{array}{c}\text { Minimum/ } \\
\text { Maximum }\end{array}$ \\
\hline Age in years & $31.88 \pm 3.04$ years & $24 / 40$ years \\
\hline Gravidity & $3.72 \pm 1.41$ & $01 / 06$ \\
\hline Parity & $3.0 \pm 1.63$ & $01 / 06$ \\
\hline $\mathrm{Hb} \%(\mathrm{~g} / \mathrm{dl})$ & $8.8 \pm 0.99 \mathrm{Hb} \%$ & $\begin{array}{c}7.5 / 10.6 \mathrm{Hb} \% \\
(\mathrm{~g} / \mathrm{dl})\end{array}$ \\
\hline
\end{tabular}

Table-I. Descriptive statistics of age, gravidity, parity, $\mathrm{Hb} \%(n=96)$

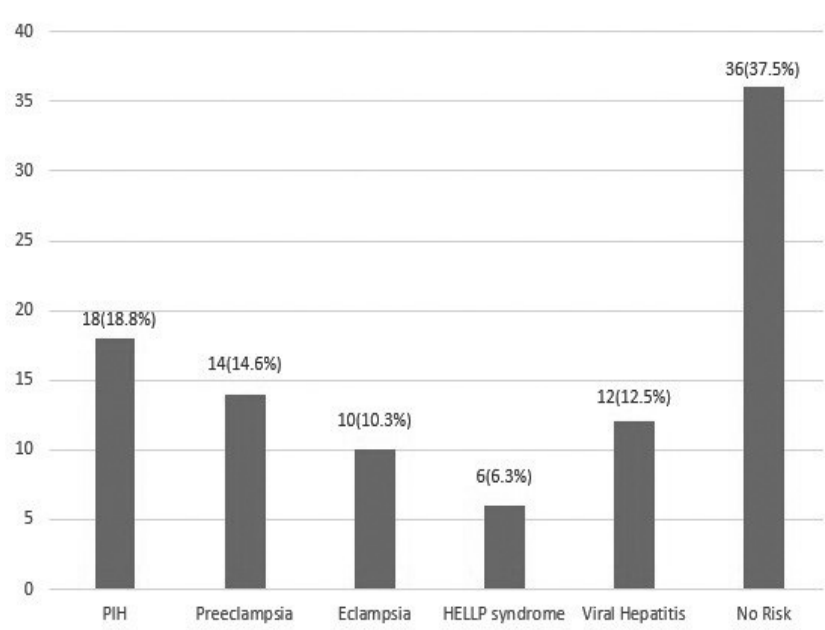

Figure-1. Risk factors related to thrombocytopenia $(n=96)$ 


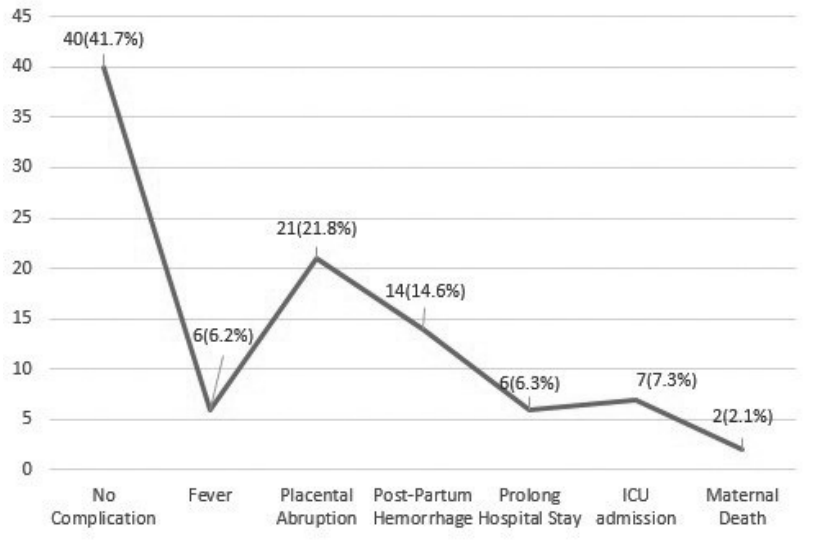

Figure-2. Maternal outcome related to thrombocytopenia $(n=96)$

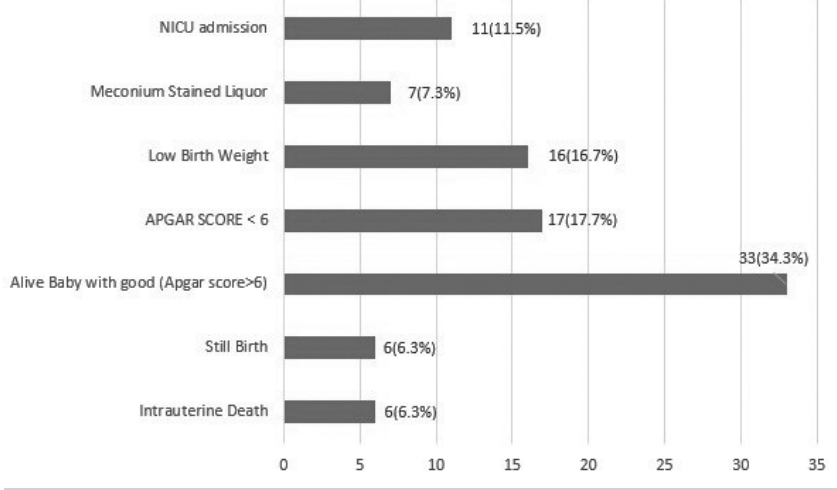

Figure-3. Fetal outcome related to thrombocytopenia $(n=96)$

\section{DISCUSSION}

Thrombocytopenia in pregnant women is uncommon and is about $10 \% .^{15}$ The disease is usually diagnosed incidentally while undergoing the routine biochemical investigations like Complete Blood Count. This investigation shows decreased platelet count that has not been causing symptoms to the patient. In our study, the prevalence of gestational thrombocytopenia was $37.5 \%$. In some studies conducted on gestational thrombocytopenia, prevalence was $58.2 \%$ and platelet count was below $100 \times 10^{9} /$. Pre-eclampsia was found to be frequent cause in those studies. But in our study, prevalence of this disease is a little bit lower and the preeclampsia was found to be on $3^{\text {rd }}$ number as risk factor of gestational thrombocytopenia. $14.6 \%$ patients had preeclampsia as risk factor. $37.5 \%$ patients had no any risk factor to develop thrombocytopenia during pregnancy. ${ }^{15,16}$
Regarding the maternal complications, $41.7 \%$ patients developed no any complication. Abdella and lee reported $26.8 \%$ patients developed placental abruption but in our study it was only $21.8 \% .^{15,17}$ Webert et al reported in study that the median age of patients suffering from this disease was 26 years. In our study maternal age incidence was also found to be similar. ${ }^{17}$

The fetal outcome was $34.3 \%$ alive babies with good APGAR score. Low birth weight and IUGR was noted in women suffering from Hypertension during antenatal period. Adverse peri natal outcome was mostly due to preeclampsia, HELLP syndrome and the group of rarer causes including DIC, familial TTP, myloproliferative diseases. In our study, we found not a single case of DIC and HELLP syndrome. McCrae concluded that hypertension during pregnancy commonly cause severe IUGR. ${ }^{15,18}$

It is fact that gestational thrombocytopenia usually does not cause any pregnancy related complication for mother as well as neonate. Thrombocytopenia in a neonate is very rare and is treated accordingly without any fatal complications as is unveiled by McCrae and Cook et al. ${ }^{16,19}$

In another study, there were no any maternal complications except developing infected wound at surgical site. Likewise, neonatal complications were also negligible. But the neonates Complete Blood Count showed platelet count less than 1 $\mathrm{lac} / \mathrm{mm}^{3}(p=0.014)$. It indicates that neonates of pregnant patients suffering from GT must undergo the routine blood investigations in order to detect any hematological complications. This study of neonatal thrombocytopenia is contradictory to other studies which do not accept gestational thrombocytopenia as cause of neonatal thrombocytopenia. Our study also concludes that gestational thrombocytopenia is not causative risk factor for neonatal thrombocytopenia., ${ }^{7,20}$

\section{CONCLUSION}

Thrombocytopenia is a relatively common occurrence in pregnancy. Diagnosis is largely 
dependent on timing of its onset, severity of the thrombocytopenia, and the association with other abnormalities. As most treatment recommendations have been based on observational reports, optimal management of mother and safe delivery of the newborn, the most common risk factor associated with gestational thrombocytopenia was found to be hypertensive disorder of pregnancy $42(43.75 \%)$. Hemorrhage including antepartum and postpartum was most significant complication in our study. More than half $63(66 \%)$ of study population suffered from adverse fetal outcome including perinatal death. Copyright $\subset 30$ April, 2019.

\section{REFERENCES}

1. Eltawel M, AlHarbi T, AlJamaan K, Alsaif S, Ali Y, Salam $M$, Forsythe PL. A prospective study on the incidence and outcomes of neonatal thrombocytopenia at a Tertiary Care Facility in Central Saudi Arabia. Advances in Neonatal Care. 2018 Oct; 18(5):E.

2. Gupta AK, Kumari S, Singhal A, Bahl A. Neonatal thrombocytopenia and platelets transfusion. Asian $\mathrm{J}$ Transfus Sci. 2012; 6(2):161-164.

3. Petermann R. Thirty years of platelet immunology in fetal and neonatal alloimmune thrombocytopenia management, current situation. Transfus Clin Biol. 2017; 24(3):166-171.

4. Patel K, Williams SF. Thrombocytopenia in pregnancy. Topics in Obstetrics \& Gynecology. 2019 Mar 15; 39(4):1-5.

5. Dahmane Ayadi I, Ben Hamida E, Youssef A, Sdiri Y, Marrakchi Z. Prevalence and outcomes of thrombocytopenia in a neonatal intensive care unit. Tunis Med. 2016; 94(4):305-308.

6. Espinoza JP, Caradeux J, Norwitz ER, Illanes SE. Fetal and neonatal alloimmune thrombocytopenia. Rev Obstet Gynecol. 2013; 6(1):e15-e21.

7. Sainio S, Kekomaki R, Riikonen S, Teramo K. Maternal thrombocytopenia at term: A population-based study. Acta Obstet Gynecol Scand. 2000; 79(9):744749.

8. Burrows RF, Kelton JG. Thrombocytopenia at delivery: A prospective survey of $\mathbf{6 7 1 5}$ deliveries. Am J Obstet Gynecol. 1990; 162(3):731-34.
9. Bockenstedt P. Thrombocytopenia in pregnancy. Hematology/oncology clinics of North America. 2011; 25(2); 293-310.

10. Vyas R, Shah S, Yadav P, Patel U. Comparative study of mild versus moderate to severe thrombocytopenia in third trimester of pregnancy in a Tertiary Care Hospital. NHL J Med Sci. 2014; 3(1):12-6.

11. Gernsheimer T, McCrae KR. Immune thrombocytopenic purpura in pregnancy. Curr Opin Hematol. 2007; 14(5):574-580.

12. Knight M, Nelson-Piercy C, Kurinczuk JJ, Spark P, Brocklehurst P. A prospective national study of acute fatty liver of pregnancy in the UK. Gut 2008; 57(7):951956.

13. Tejashwini VB, Spoorthi BS, Saryu Sain. A comparative study of change in platelet count in pregnancy and puerperium. IJCAP 2015; 2(2):108- 110.

14. Goldman BG, Hehir MP, Yambasu S, O'donnell EM. The presentation and management of platelet disorders in pregnancy. European journal of haematology. 2018 Jun; 100(6):560-6.

15. McCrae KR. Thrombocytopenia in pregnancy. ASH Education Program Book. 2010 Dec 4; 2010(1):397402.

16. Elhassade AS, Nasser AB. Thrombocytopenia at different stages of pregnancy. Int $\mathrm{J}$ Clin Biomedical Rese. 2016 May 9; 2(2):1-3.

17. Ahmad R, Shamsi TS. Thrombocytopenia in pregnancy; A Pakistani perspective. National J Health Sci. 2018; 3:71-75.

18. Bergmann F, Rath W. The differential diagnosis of thrombocytopenia in pregnancy: An interdisciplinary challenge. Deutsches Ärzteblatt International. 2015 Nov; 112(47):795-9.

19. Kasai J, Aoki S, Kamiya N, Hasegawa Y, Kurasawa K, Takahashi T, Hirahara F. Clinical features of gestational thrombocytopenia difficult to differentiate from immune thrombocytopenia diagnosed during pregnancy. Journal of Obstetrics and Gynaecology Research. 2015 Jan; 41(1):44-9.

20. Brojer E, Husebekk A, Dębska M, Uhrynowska M, Guz K, Orzińska A, et al. Fetal/neonatal alloimmune thrombocytopenia: Pathogenesis, diagnostics and prevention. Archivum immunologiae et therapiae experimentalis. 2016 Aug 1; 64(4):279-90. 


\title{
Ships don't sink because of the water around them; ships sink because of the water that gets in them. Don't let what's happening around you get inside you and weight you down.
}

\author{
“Unknown"
}

\section{AUTHORSHIP AND CONTRIBUTION DECLARATION}

\begin{tabular}{|c|c|c|c|}
\hline Sr. \# & Author(s) Full Name & Contribution to the paper & Author(s) Signature \\
\hline 1 & Aasma Naz Qureshi & $\begin{array}{l}\text { Conception and design, Statistial } \\
\text { expertise, Critical revision of the } \\
\text { article for important intellectual } \\
\text { content. }\end{array}$ & $d$ \\
\hline 2 & Sakina & $\begin{array}{l}\text { Data collection critical revision of } \\
\text { the article for important intellectual } \\
\text { content. }\end{array}$ & \\
\hline 3 & Tabinda Taqi & Drafting of the article. & \\
\hline 4 & Hafiza Khatoon & Data collection. & \\
\hline 5 & Irfan Ahmed & Drafting of the article. & \\
\hline
\end{tabular}

